\section{Venereal Disease}

Q.-What has been the peak rate of syphilis and gonorrhoea in the B.A.O.R. since the end of the war? Is the increase in the incidence in venereal disease shown in the Ministry of Health Report for the year 1946 likely to be a peak figure, or has there been a further rise in 1947? Can any explanation be offered for the fact that this expected post-war rise in venereal disease is delayed as compared with the corresponding rise after the 1914-18 war? Is it irue that the spirochaete can be transmitted in the seminal fluid for three to five years after a supposed "cure"? How long after the cure of syphilis is marriage permissible?

A.-Figures for syphilis and gonorrhoea rates in the B.A.O.R. up to date are not available, but probably the highest were reached in 1946, when for one quarter they were in the neighbourhood of an equivalent annual ratio of 80 to 90 per 1,000. The civilian rates in this country for fresh infections with syphilis and gonorrhoea during 1947 fell well below those for 1946. If it is admitted that the expected post-war rise in V.D. was delayed longer after the 1939-45 war than after the 1914-18 war, and it is not so clear that it was, there are many possible explanations, none of which is very convincing. Spirochaetes have been demonstrated in the seminal fluid of latent syphilitics some years after the date of infection; such persons would presumably be able to transmit their infection. It is usually considered safe to allow a syphilitic person to marry when five years have elapsed from the time of infection, but in the case of a syphilitic woman it is wise to recommend antisyphilitic treatment during any pregnancy in order to ensure the birth of a non-syphilitic child.

\section{Treatment of Diverticulitis}

Q.-How should one treat loss of weight and increasing constipation in a case of diverticulitis of the lower colon? $A$ man aged 57 had been diagnosed by a competent radiologist as suffering from diverticulitis. He still plays golf and tennis. Most of his teeth have been extracted, and it is only within the last year that he has suffered from increasing constipation. He now complains of flatulence and abdominal discomfort after defaecation-his bowels never seem to be properly emptied. He has lost over 1 st. (6.35 kg.), and his weight is now $10 \mathrm{st} .5 \mathrm{lb}$. $(65.77 \mathrm{~kg}$.$) . Myalgia and weakness are present in both groups$ of extensor muscles of the thighs. He eats anything except food containing "roughage," and takes emuls. paraff. liq. c. phenolthal., two dessertspoonfuls every night. Is there any other treatment, and what is the prognosis?

A. - The general symptoms of which this patient complains are severe for simple diverticulosis, even when accompanied by diverticulitis: obviously the possibility of carcinoma must be considered. The description suggests that the lesion would be within view of the sigmoidoscope. Provided malignant disease has been excluded, the indications are to maintain regular evacuations with liquid paraffin and a low residue diet. It sounds as though these measures were now losing their efficacy and that recurrent episodes of partial obstruction were taking place, hinting at a progressive stenosis of the bowel's lumen. If this is so, surgical treatment will become necessary, and it would be advisable to consult a surgeon before complete obstruction supervenes and the patient's health deteriorates further.

Dangers of Cinchophen
Q.-I have been warned of the danger of using cinchophen for the removal of excess uric acid in the blood. Can you suggest any safer alternative? What are the principal dangers of cinchophen?

A.-Cinchophen is the only efficient substance to increase the excretion of uric acid. Its principal danger is that it may cause hepatitis, and this has been known to go so far as to cause jaundice and death. This is, however, a very rare occurrence. In 1931 White estimated the annual consumption of cinchophen in the United States to be $90,000 \mathrm{lb}$. $(40,823 \mathrm{~kg}$.), so that the proportion of cases in which liver damage occurs must be very low. Cinchophen irritates the stomach, therefore while it is being used sodium bicarbonate should also be given (though not simultaneously); on the first day $15 \mathrm{~g}$. (225 gr.) of sodium bicarbonate and 5-10 g. on the following days. This also keeps the urine alkaline. Plenty of fluid should be taken.
Other points about the toxicity of cinchophen were discussed in a question and answer published on Aug. 28 (p. 450).

\section{Hypoplastic Anaemia}

Q.-Are x-ray therapy, electrotherapy, sulphonamides, or residence or a visit to the Tropics contraindicated in cases of hypoplastic anaemia?

A.- In cases of hypoplastic anaemia there is no contraindication to electrotherapy. Residence in the Tropics is contraindicated only in so far as it carries some additional risk of disease-e.g., amoebic dysentery-which a person with hypoplastic anaemia could less well support. $X$-ray therapy is contraindicated, although evidently there are circumstances in which it would be better to have $x$ rays and risk the possible ill effects on the bone-marrow rather than go without them and suffer still worse effects. Much the same considerations apply to the use of sulphonamides; certainly one would not use them unless the patient had an infective condition which had failed to respond to penicillin and other measures.

\section{NOTES AND COMMENTS}

When was Hughlings Jackson Born ?-Dr. E. H. DeRRICK (The Queensland Institute of Medical Research, Brisbane) writes: Although authorities agree that Hughlings Jackson was born at Green Hammerton, in Yorkshire, they disagree as to whether this auspicious event occurred in 1834 or 1835. Supporters of 1834 are Power and Thompson's Chronologia Medica, Garrison's History of Medicine, and Dorland's and Gould's Medical Dictionaries. On the other hand the obituary in the British Medical Journal $(1911,2,950)$ and Bailey and Bishop's Notable Names give 1835. The Section. of Neurology of the Royal Society of Medicine celebrated the centenary on April 4,1935 (Journal, 1935, 1, 769). This disagreement about such an illustrious figure is surprising. Can it be authoritatively settled ?

Air Conditioning.-Lieutenant-Colonel H. G. G. ROBERTSON writes from Hamburg: In "Any Questions?" (Aug. 14, p. 363) a correspondent asks about air conditioning. Perhaps the following brief outline of the principles of air conditioning may be helpful. By means of a pump air is drawn from outside through a filter which rids it of gross particles. It is then passed through a screen of sprayed water at a temperature well below that which is finally required of the air. This washes it, cools it, and raises its humidity to saturation point. The air is then heated to the desired temperature, and, as hot air is capable of absorbing more water vapour than cold air and the actual amount of water remains the same, the relative humidity falls. By suitably adjusting the temperature of the cooling water it is possible to obtain almost any desired temperature and relative humidity in the air that enters the room. It is, of course, essential that doors and windows be kept closed to prevent the entry of the outside air.

\section{Corrections}

In amplification of its statement on the "Streptomycin Treatment of Tuberculosis" the Ministry of Health adds that streptomycin wil nevertheless still be available for the treatment in any hospital of cases of acute miliary, meningeal, and ulcerative tracheo-bronchial and laryngeal tuberculosis, but in special instances applications for it should now be made to one of the Regional Distribution Centres instead of, as formerly; to the Ministry of Health.

Messrs. Henry Kimpton inform us that they are the English agents for Clinical Laboratory Methods and Diagnosis, by R. B. H. Gradwohl, noted in "Books Received" (Sept. 4, p. 478), and that the price is 10 guineas.

We regret that owing to a printing error the name of $\mathrm{Mr}$. John Gilroy, who painted the presentation portrait of Sir John Herbert Parsons (Sept. 11, p. 529), was mis-spelt.

Dr. M. H. Logg (Medical Superintendent, Grove Park Hospital, London, S.E.12) writes : Referring to the announcement regarding the distribution of streptomycin in your issue of Sept. 11 (p. 527) I would call your attention to the fact that the telephone number I would call yourtal is Lee Green 1077-and not as printed, Lee Green 1547 (which happened to be the earlier telephone number until 1946).

All communications with regard to editorial business should be addressed to TH EDITOR BRITISH MEDICAL LONDON, W.C.1. TELEPHONE: EUSTON 2111. TEI.EGRMS: Aitiology. Westcent, London. ORIGINAL ARTICLES AND LETTERS forwarded fo publication are understood to be offered to the Brittsh Medical Journal alone. publication are understood to be of communicate with the Publishing Manager. B.M.A. House, Tavistock Square, W.C.1, on receipt of proofs. B.M.A. House, Tavistock Square, B.M.A. House, Tavistock Square, London, W.C.1 (hours 9 a.m. to 5 p.m.) B.M.A. House, Tavistock 211 . TELEGRAMS: Britmedads, Westcent, London. MEMEPERS : SUBSCRIPTIONS should be sent to the SECRETARY of the MEMBERS' SUBSCRIPTIONS should begrams : Medisecra, Westcent, London. B.M.A. Scotrish OFFICE: 7, Drumsheugh Gardens, Edinburgh. 